\title{
Effects of Teacher Scaffolding on Students' Oral Reading Fluency
}

\author{
Chanyalew Enyew ${ }^{1}$, Abiy Yigzaw ${ }^{2 *}$ and Mesafint Muche \\ ${ }^{1}$ Faculty of Behavioural Sciences and Education, Bahir Dar University, Bahir Dar University, P.O. Box: 79, \\ Bahir Dar, Ethiopia \\ ${ }^{2}$ Department of English Language and Literature, Bahir Dar University, Bahir Dar University, P.O. Box: 79, \\ Bahir Dar, Ethiopia \\ ${ }^{3}$ Department of English Language and Literature, University of Gondar, Gondar, Ethiopia
}

\begin{tabular}{ll}
\hline \multicolumn{1}{c}{ Abstract } & Article Information \\
\hline This study examined the effects of an English teacher's scaffolding on students' & Article History: \\
passage reading fluency in Dona Berber Primary School, Ethiopia. Thirty Grade 4 & Received : 02-11-2015 \\
students participated in a quasi-experimental pre- and post-test research design to & Revised $: 23-12-2015$ \\
examine changes in their reading strategies and fluency as a result of teacher & Accepted : 28-12-2015 \\
\cline { 2 - 2 } scaffolding. Oral reading fluency tests, two structured classroom observation & Keywords: \\
checklists, and interview were used as data collecting instruments. The quantitative & Early Grade Reading Assessment \\
data were analyzed using t-test and percentages whereas the qualitative ones were & Oral Reading Fluency \\
meta-explained. Both the quantitative and qualitative data indicated improvements in & First Cycle Primary \\
students' reading and strategy use. The findings suggest that scaffolding reading & Scaffolding Reading Experience \\
strategy instruction is effective in enhancing students' oral reading fluency of grade 4 & Scaffolding Reading Strategies \\
\cline { 2 - 2 } students. Therefore, it is recommended that scaffolding reading strategy training be & *Corresponding Author: \\
given to English language teachers and students to make the reading lesson & Abiy Yigzaw \\
engaging and student-friendly. Besides, it is recommended that a detailed future & E-mail: \\
investigation and intervention be made in the area. & yigzawabiy2014@gmail.com \\
Copyright@2015 STAR Journal, Wollega University. All Rights Reserved.
\end{tabular}

\section{INTRODUCTION}

Beginning from the commencement of modern education in 1908, English as a foreign language teaching/learning has got attention and increased importance in Ethiopia (Abebe, 2012; Abiy, 2007; Amlaku, 2010). It is widely observed that English has been used in many areas such as education, politics, tourism, economics, electronics, telecommunication, culture, diplomacy, business, medicine and research. English is also used as a means of disseminating information and development in science and technology (Abebe, 2012; Abiy, 2007; Gessesse, 1999).

Therefore, it is necessary for Ethiopian students to have a good command of the English language to be competent enough in their academic area and various other purposes indicated above. In Ethiopia, English is taught as a subject beginning from grade one and is used as a medium of instruction in second cycle primary schools (in some regions), senior secondary schools and higher learning institutions. English is mostly used for academic purposes in the country, and there is a high demand for reading to learn the English language better and study other disciplines. This signifies the substantial role reading plays both in language and general education (Abiy, 2007; Gessesse, 1999).
Amlaku (2010; See also Ethiopian Ministry of Education, 2008) has indicated that over the past decades, major actions have been taken in teaching the English language skills to satisfy the growing needs in Ethiopia. One of the mechanisms for enhancing quality of children's learning is improving their reading skill so that it will have pivotal roles in increasing their learning of other subjects and the English language skills (Amlaku, 2010; Transitional Government of Ethiopia [TGE], 1994).

Students' acquisition of the reading skill is indispensable (USAID Ethiopia, 2011; MoE, 2008). One of the ways children develop their reading is through oral reading. Hence, early grade oral reading fluency development in English has become a national concern. This is because good oral reading fluency in $L_{1}$ or EFL/ESL leads to better reading comprehension and overall academic achievement (Chall, 1983). Children who gain early reading oral fluency acquire the instruments to steadily grow in their knowledge and reading skills compared to those who do not get the skill. As Piper (2010) and Stanovich (1986) affirmed, students who had difficulty in early grade reading fluency mostly continue to experience failure in later levels of education. 
Practice in oral reading fluency helps students read fluently. Research (for example, Adams, 1990) on students' oral reading fluency has shown that it increases their sound to be smooth and natural. It is suggested that fluency boosts the integration of intonation, inflection, phrasing, pacing, and word recognition which are essential for students to comprehend a text. Research results recommend that reading fluency can be attained when it is done using choral, echo, fluent, paired, and independent reading. Repeated word, phrase, short paragraph reading and providing direct instruction and feedback have a facilitative role (American Institutes for Research [AIR], 2012; Fitzgerald and Graves, 2004; National Reading Panel [NRP], 2000).

In the past, oral reading fluency was given less attention than reading comprehension, so students used to put less effort into word recognition. Currently, oral reading fluency has received prominence in students' word recognition and text comprehension (Taguchi, Takayasu and Gorsuch, 2004). Studies have indicated that oral reading fluency can help students group words within a sentence into phrases; and this makes reading comprehension easier. Accordingly, fluency is a means of recognizing the words/phrases in a text quickly, smoothly, and accurately in a specified time (Hudson, Lave and Pullen, 2005; NRP, 2000).

Rodgers and Rodgers (2004) contend that reading teachers should scaffold oral reading fluency until they become independent readers. Teacher scaffolding is an effective instrument in helping students develop their oral reading fluency on word recognition, prosody and general reading (Beck and McKweowen, 2001; Rodgers and Rodgers, 2004; Taylor, Pearson, Clark, and Walpole 2000; and Scharlach, 2008). A research on fourth grade students disclosed that the most oral fluent readers had the highest comprehension scores. Further evidence showed that a decrease in oral reading fluency had resulted in low reading comprehension (Talada, 2007).

Although few studies have been conducted on primary level English language reading problems in Ethiopian second cycle primary schools (Grades5-8) (Dawit, 2014; Gemechis, 2014; Micheal, 2003) and first cycle primary schools (Grades1-4) (Chefena, 1988; Dereje, 2012; Eba, 2014; Mesfin, 2008; Zenebe, 2000), no studies so far, to the knowledge of the researchers, have addressed teacher scaffolding reading strategies to improve students' oral reading fluency in first cycle primary schools. Hence, this study aims at investigating teacher scaffolding strategies intervention as a means of improving students' oral reading fluency skill in grade 4 .

Oral reading fluency is defined as the ability to translate letters into sounds, unify sounds into words, process connections, relate text to meaning, and make inferences to fill in missing information in order to measure the overall reading competence (Fuchs et al, 2001). Hence, translation of text into spoken language supports students to combine these tasks in a seemingly effortless manner (automaticity) (NRP, 2000). In oral reading fluency classrooms, students receive guidance or support through teacher scaffolding which has a significant effect on students' reading (NRP, 2000). Effective fluency classroom procedures include repeated reading of the same text, in which a student receives feedback from a teacher or other coach, and assisted reading, in which a student reads varied texts with support from a teacher or other skilled reader, or reads after listening to a skilled reader (NRP, 2000). In the while (during) reading strategies stage, the EFL teacher either reads out the story loud to the whole class or supports the students to read it loud. The teacher reads to help adjust the speed as well as model appropriate pronunciation (Talada, 2007)

Teachers need to listen to students read aloud and observe to make judgments about their progress in oral reading fluency by paying closer attention to each critical aspect of fluent reading, like word-reading accuracy, rate, and prosody accomplished through timed readings Timing of a student's reading of connected text allows a teacher to observe the number of words read correctly and the number of errors made in a given duration (Fuchs et al., 2001). It is advantageous to use timed readings to measure and increase word-reading accuracy and passage-reading rate based on books or passages the student has read before that are at an independent reading level supported by teacher scaffolding (Samuels, 2006).

Scaffolding is a temporary interactional process between teachers and students until students become autonomous readers. The concept of scaffolding reading strategy instruction was rooted from Vygotsky's (1978) theory of learning and his concept of the zone of proximal development (ZPD). Vygotsky considers all knowledge is social in nature and believes that learning occurs when students are introduced with new lessons and activities. This means that the more students get familiarized with their learning, the less the application of scaffolding would be (Vygotsky, 1986). Wood, Bruner and Ross (1976:90) have defined scaffolding, as a process that "enables a child or novice to solve a task or achieve a goal that would be beyond his unsatisfied efforts." This definition emphasizes the collaborative effort of the teacher and students in constructing knowledge, the teacher supporting the student. In his theory, learning is formed effectively through the ZPD in social interaction with others. There are arguments for support and strategy in reading classrooms, that classroom teacher scaffolding backed-up by reading strategies can help primary grade students improve their oral reading fluency. Hence, a certain level of scaffolding is essential for primary level students (grade 4 students in this case) to be able to draw on these strategies and apply them properly in their reading.

In this regard, Williams (1984) points out that the most important part of teacher's job is to develop learner strategies which are appropriate to the learners. It could be emphasized that in the reading class, the teacher should encourage students to create their own meaning from their reading by helping them to bridge the linguistic and cultural gap that students experience in reading a text rather than to impose the teacher's interpretation of the meaning upon them. To reduce such obstacles, teacher scaffolding can preferably be presented to students with a kind of instruction that is intentionally and carefully taught, through which they can learn to become independent and self-regulated readers.

The researchers believe that scaffolding at early stage, at early reading stage is essential. It is also reported by some experts. For instance, Clay (1990) asserts that 
children who do not develop oral word reading fluency in language during their first years of education are up to six times more likely to experience reading problems when they go to school. This argument is also supported by Juel (1988) who examined children's reading in his studies. It was found out that children who are successful in oral reading fluency by the end of grade one will have good reading comprehension throughout their schooling and later in life. With this belief, the researchers have opted to study first cycle primary level, grade 4 students particularly.

The problem of using English across the curriculum still continues to be acute, notwithstanding the significant role it maintains in the country (Abiy, 2007; Michael, 2003). The Ethiopian English Early Grade Reading Assessment (EGRA) of first cycle primary students except grade one indicated far below the expected results (AIR, 2012). The preliminary results disclosed that about twothirds of the students did not demonstrate the knowledge and skills MOE expected; i.e. they did not meet the minimum learning competencies for the level (AIR, 2012; Gemechis, 2014; Piper, 2010). Tsehay's (2013) study in the Amhara Region has also shown that students' early reading achievement was low. One of the causes for this might be teachers' approach in teaching reading. Most teachers focus much on teaching of the alphabet or words; and this delays students' development of reading competency (AIR, 2012; Gemechis, 2014; Micheal, 2003). They engaged students with practice and drill rather than supporting (scaffolding) them to develop their reading fluency (Moore, DeStefano, and Adelman, 2010).

In general, it may be concluded that the existing reading instructional approach in primary schools in Ethiopia is not helping students to improve their oral reading fluency (Piper, 2010). As recommended by USAID/Ethiopia, a systematic intervention targeting reading instruction and the provision of reading materials are essential (AIR, 2012; Piper, 2010). It is suggested that teaching reading strategy is important. Hence, the purpose of this study was to examine the effects of English language teacher's scaffolding on oral reading fluency of Grade 4 students at Dona Berber Primary School of Bahir Dar, Ethiopia. Based on the above general purpose, the following research question was formulated.

What is the effect of English language teacher's scaffolding on Grade 4 students' oral reading fluency?

The study is expected to contribute three-fold significance: teachers can construct a deeper understanding of scaffolding in EFL reading, and use it in their classrooms, and thereby improve students' oral reading fluency.

\section{MATERIALS AND METHODS}

This study attempted to investigate the effects of scaffolding reading strategies on grade 4 students' oral reading fluency in one government Primary School of Bahr Dar, Ethiopia, by 2014 academic year. The study employed a quasi-experimental pre- and post-test research design to examine changes in the students' reading strategies and fluency as a result of teacher scaffolding. A quasi-experimental research design was chosen because this design allowed the researchers to use preferably intact classroom setting in which random assignment of participants of the study to different conditions was not mandatory (Creswell, 2009). Hence, this study applied an intact classroom by taking a section of Grade $4(\mathrm{~N}=30)$ students to look into whether or not the EFL teacher scaffolding improves students' English oral reading fluency.

\section{The preparation of the reading lessons and activities at different stages}

In order to design the reading lessons, the Scaffolding Reading Experiences (SRE) reading strategy framework was selected. The SRE is found to be an appropriate EFL strategy instruction that is well-structured and easily applicable in contexts where both teachers and students have little past experiences in employing scaffolding reading strategies.

For the purpose of this study, the Scaffolding Reading Experience model was selected as an instrument for the intervention as it encompasses all the necessary scaffolding reading strategies for EFL learners at all grade levels. These scaffolding strategies are: the pre-duringpost-reading strategies. In pre-reading, introducing the title/topic of the story, giving direction, making logical predictions, setting purpose for reading, pre-teaching new, key and difficult words, connecting background knowledge, using student native language and describing reading strategy are incorporated. The during reading strategies include: teacher loud reading, student loud reading, and student silent reading, answering and asking questions and using strategies in self/independent reading. The after-reading strategies comprised using questions to interpret, analyze, evaluate, and promote higher-order thinking, using graphic organizers to recall information, answering questions and summarising the story using their native language and independent use of the strategy.

For this study, teacher loud reading, individual student loud, choral reading and silent pair reading were used. This model was used to design a detailed reading lesson plan in order to teach the contents of oral reading fluency. The lesson plan was adapted from teacher's roles and lesson templates fidelity checklist designed by Butler (2007), Donaldson (2011), and Fitzgerald and Graves, 2004).

\section{Instruments}

\section{Oral Reading Fluency Tests}

In Ethiopia, there are no available standardized tests that could measure oral reading fluency of primary school students except the Ethiopian English Early Grade Reading Assessment (EEEGRA) which was piloted and implemented by American Institutes for Research [AIR] (2012) on 19,800 randomly selected grades 2-4 students in 330 randomly selected schools drawn from the nine regions and two city administrations. For this research, a few elements of EEEGRA were adapted and used to construct a pre-and post teacher-made tests by two Grade 4 English language teachers to assess students' oral reading fluency. Attempts were made to construct both valid and reliable tests, paying attention to make sure that the difficulty level of words was appropriate to Grade 4 students. Besides, the texts used to prepare the pre-test and post-test items had also a similar level of difficulty in terms of words, length of passage and text structure with that of the Grade 4 reading textbook. Care was also taken to follow the familiar formats and test procedures of the 
school and the students. Two teachers from the same school and two secondary school English teachers were requested to evaluate the clarity and difficulty level of the tests in the pre-and post-tests. Finally, the tests were commented on by a measurement and evaluation instructor and two instructors (all PhD holders) in TEFL at Bahr Dar University. Some modifications were made on a few of the items based on the comments given by the scholars. Before the students took the tests, clear instructions about the passages were given.

The two Oral Reading Fluency Tests (pre-and posttests), which were short narrative paragraphs of 60 words each, were piloted in Kulkual Meda first cycle primary school. Fifteen students were selected for the purpose and the coefficient values of the computed Cronbach alpha for the pre- and post-tests were 0.74 and 0.77 , respectively; and these values fall within the acceptable range of reliability (Manion and Morrison, 2007).

\section{Classroom Observation Checklist and Field Notes}

A categorical ("Yes" or "No") structured/closed-item observation checklist with 6 items was adapted from teacher's roles and lesson templates fidelity checklists designed by Butler (2007), Donaldson (2011), and Fitzgerald and Graves (2004) to see how reading strategies were employed. Thus, eight round observations were conducted by the researchers and checked and rated how the teacher implemented scaffolding reading strategies in teaching oral reading fluency.

\section{Focus Group Discussion/Reflection}

Eventually, using an open-ended focus group discussion with students and teacher reflection, the researchers analysed the data about how the teacher implemented scaffolding reading strategies during her reading classes, and about the benefits the students have gained to improve their oral reading fluency.

\section{Procedures}

\section{Training of the Classroom Teacher}

Having secured permission from the school's vicedirector, director, department head and the classroom teacher, the researchers started the training on the classroom teacher scaffolding reading instruction. The teacher scaffolding reading strategy intervention was planned to be implemented by one Grade 4 regular classroom teacher. Butler (2007) recommended that, prior to the intervention, introducing the scaffolding reading strategy instruction to the teachers and encouraging them to apply in their lessons is essential. Hence, a training manual that lasted 8 hours training was prepared by the researchers. During the training, practical scaffolding reading strategy training supported by trainee reflection and trainer feedback was given for the regular teacher assigned to teach the selected class. Another teacher was also trained to substitute the regular teacher in case of emergency. Training the two teachers created a collaborative and interactive scenario during the training. The training was given by the researchers of this study. Exemplary and demonstrative samples were given to the teachers on why, what, and how of the scaffolding reading strategy throughout different units of the reading passage. This was done to see whether or not the scaffolding reading strategy was implemented regularly and actively during the actual reading classes by the classroom teacher.
On the first day of training, the researchers introduced the Scaffolding Reading Experience (SRE) to the teachers as one of the useful reading strategies in improving students' oral reading fluency. The introduction constituted the rationale and the pre, during and postreading strategies involved in SRE. The reading text was selected from Grade 4 Student Text (MoE, 2011), "Anito", from which each of the SRE phases was first introduced through gapped lecture, thinking aloud, demonstration, and discussion. Then, trainer-trainee discussion and reflection was accompanied by trainees' comments for improvement. Based on the feedback, the next round trainings were re-planned.

In the next two round trainings (for 2:30 hours session each), the teachers continued practicing the SRE using the selected texts in the manual, Teacher's guide and the Grade 4 textbook. Teachers were encouraged to apply the SRE and discussed each other how to apply SRE in reading classes. After answering each question in the exercise of the manual and the textbook, teachers were then invited to exchange their notebooks to help them check what and how they did. In the pre-reading stage, teachers were encouraged to activate background knowledge. In the during/while reading, teachers practised how they would teach teacher loud reading, student loud reading, student silent reading, answering and asking questions and using strategies in self/independent reading. And during the post reading, they practised how to encourage students and re-read and help each other and read independently. Generally, teachers were trained in all the sessions how they could plan and apply the SRE in their daily reading lessons and activities.

\section{Procedure for Scoring}

The instruments used to measure the intervention were a pre-test and a post-test, students' response structured list, researchers' observation checklist and Focus Group Discussion.

\section{a) Oral Reading Fluency Test}

The Reading Passage /Oral Reading Fluency selected for the test was a sixty-word passage timed to last for 1 minute having one mark for each word read and with a total of $60 \%$ marks. A pre-test was given individually to each Grade 4 student $(\mathrm{N}=30)$ of Dona Berber Primary School by two EFL teachers before the intervention had begun; and a post-test was also given after the intervention was completed. Next, the researchers/ assessors set the timer on 1 minute. They started the timer when a student read the first word. They were following along and clearly marked any incorrect words with a slash (/). When a student hesitated below 4 seconds and made self-correction, it was counted as correct. However, if the student hesitated for 4 seconds and beyond, the assessors provided the correct answer and marked the word as incorrectly read. When the timer reached 0 , the assessors told the student (the reader) to stop. Finally, they marked the final word read with a bracket ( ]). Having done this, the score was calculated by counting the number of words each student read aloud correctly in one minute out of a total of $60 \%$ score.

\section{b) Students' Observation Checklist}

The Scaffolding Reading Experience checklist, which was with six scaffolding reading strategies, was filled by the students and analyzed. The students' observation checklist responses were scored in two rating scales: (2) 
Chanyalew Enyew et al.,

Yes and (1) No. The percentage score of responses on each strategy lesson was calculated. This enabled the researchers to see how adequately students practiced the Scaffolding Reading Experience (SRE) during the whole lessons and determine the extent to which the use of SRE strategy has improved students' oral reading fluency as the lesson progressed.

\section{c) Researchers' Observation Checklist}

The structured observation reading strategy checklist, that constituted six items, was used to check the occurrence of behaviour during reading or the frequency of teacher's use of strategies in her reading classes to enhance students' reading strategy use and improve their oral reading fluency. The first lesson observation was not recorded to reduce students' fear of the researchers' presence in the classroom.
Sci. Technol. Arts Res. J., Oct-Dec 2015, 4(4): 200-207

\section{RESULTS AND DISCUSSION}

The results of the study are presented in three parts. The first part shows oral reading fluency test results of the students on the pre- and post-tests; while the second presents the students' responses regarding the observation checklist. The third, however, reports the researchers' observation results on teacher scaffolding strategy along with teacher and student reflection.

\section{Students' Oral Reading Fluency Test Scores}

The mean scores of students' on the pre-test and posttest is shown in Table 1. To measure the changes brought about by the intervention, a paired samples t-test was calculated for the pre- and post-test reading fluency test results.

Table 1: Paired samples t-test for pre- and post-test oral reading fluency scores

\begin{tabular}{ccccccc}
\hline Test results & N & Mean & Std. Deviation & t & Df & Sig. (2-tailed) \\
\hline Pre-test fluency & 30 & 31.9333 & 20.96744 & & & \\
\cline { 1 - 5 } Post-test fluency & 30 & 36.7330 & 20.66300 & & & \multirow{2}{*}{000} \\
\hline
\end{tabular}

Table 1 above shows that there exists statistically significant difference $(t=10.755, P<0.05)$ in the reading fluency scores between the pre-and post-tests of grade four students; the post-test results excelling the pre-test results. The finding is consistent with Dawit's (2014) results which indicated that the students in the intervention with teacher explicit reading strategy use. Similarly, it is also consistent with Kim and White's (2008) study results on teacher and parent scaffolding reading strategies that disclosed continuous improvement on students' oral reading fluency. Besides, Kuhn (2004) found that the emphasis given by teachers to oral reading strategies in oral fluency reading instruction has a great role in improving primary grade students' oral reading fluency and their reading comprehension achievements. The finding is also in harmony with Burch's (2007) teacher scaffolding instruction which has helped students benefit to acquire and learn to manipulate scaffolding reading strategy in a social context. The strategy encouraged students to take risks.

The highest post-test research results on students' oral reading fluency might have been achieved as a result of employing teacher scaffolding in primary grade reading instruction. So, it is assumed that the increment in reading scores might have been gained due to the intervention, which involved students' engagement. The strong significant differences exhibited in the students' oral reading fluency post-test scores possibly supports the claim that employing teacher scaffolding in reading instruction can enhance students' oral reading fluency performance. Thus, employing teacher scaffolding enhanced students' learning of new strategies, concepts and oral reading; and, as a result, they became independent learners and problem solvers (See also Burch, 2007).

Table 2: Students' $(\mathrm{N}=30)$ responses on teacher scaffolding strategy use in reading

\begin{tabular}{|c|c|c|c|c|}
\hline & On Stratoruce the toacher. & Stude & s' res & onse \\
\hline & Un strategy use, the teacner: & Item & No. & $\%$ \\
\hline & & Yes & 28 & 93.3 \\
\hline 1 & Modelled repeated oral reading fluency & No & 2 & 6.7 \\
\hline & & Total & 30 & 100 \\
\hline & & Yes & 26 & 86.7 \\
\hline 2 & Provided oral support and modelling through choral, group & No & 4 & 13.3 \\
\hline & & Total & 30 & 100 \\
\hline & & Yes & 26 & 86.7 \\
\hline 3 & Activated student individual loud reading & No & 4 & 13.3 \\
\hline & & Total & 30 & 100 \\
\hline & & Yes & 19 & 63.3 \\
\hline 4 & Encouraged student silent reading & No & 11 & 36.7 \\
\hline & & Total & 30 & 100 \\
\hline & & Yes & 22 & 73.3 \\
\hline 5 & Directed Instruction and teedoack to teacn decoding of & No & 8 & 26.7 \\
\hline & & Total & 30 & 100 \\
\hline & & Yes & 18 & 60 \\
\hline 6 & Motivated individual student's strategy use & No & 12 & 40 \\
\hline & & Total & 30 & 100 \\
\hline
\end{tabular}


Chanyalew Enyew et al.,

Table 2 indicates students' responses concerning teacher's employment of scaffolding reading. Accordingly, $93 \%$ of the students responded that the teacher modelled repeated oral reading fluency strategy at the beginning of the reading lesson. This implies that the strategy is applied both by the teacher and the students. Quite a large number of students $(86.7 \%)$ have also said that the teacher modelled the oral reading fluency teaching through choral, group or paired reading in most of the reading periods. The same number of students $(86.7 \%)$ also indicated that the teacher employed activated individual loud reading. Over $63 \%$ of the students have reported that the teacher has encouraged students' silent reading. The use of directed instruction and feedback to teach decoding of unknown words, correct expressions and phrasing was shown by $73.3 \%$ of the students. About $60 \%$ of the students have witnessed that the teacher
Sci. Technol. Arts Res. J., Oct-Dec 2015, 4(4): 200-207

motivated individual student's strategy use. From the findings, it is possible to assume that the teacher (the scaffolder), as Williams (1984) pointed out, has effectively employed the oral reading scaffolding strategies. Such use is beneficial to students' current and future reading development (Piper, 2010; Stanovich, 1986; Talada, 2007 and Samuels, 2006).

In sum, the above findings revealed that there seems to be regular strategy use, although there is difference in frequency, in teaching reading. However, encouraging student silent reading and teacher motivated individual student strategy (which are least frequent seen in comparison) use seem to require further scaffolding and practice in order to enhance students' independent oral reading fluency.

Table 3: Classroom observation results on strategy use

\begin{tabular}{|c|c|c|c|c|c|c|c|c|c|c|c|}
\hline \multirow[b]{2}{*}{ No } & \multirow[b]{2}{*}{ Teacher: } & \multicolumn{10}{|c|}{ Occurrence of Behaviours } \\
\hline & & 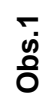 & ヘ̋ & m & $\begin{array}{l}\text { ष: } \\
\stackrel{0}{0}\end{array}$ & 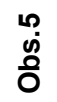 & $\begin{array}{l}0 \\
\ddot{0} \\
\stackrel{0}{0}\end{array}$ & $\begin{array}{l}\hat{p} \\
\stackrel{0}{0}\end{array}$ & $\begin{array}{l}\infty \\
\ddot{0} \\
\stackrel{0}{0}\end{array}$ & $\begin{array}{l}\bar{\pi} \\
\stackrel{0}{0}\end{array}$ & $\%$ \\
\hline 1 & Modelled oral reading fluency & & & $\mathrm{X}$ & $x$ & $\mathrm{X}$ & $x$ & $x$ & $\mathrm{X}$ & 6 & 75.0 \\
\hline 2 & $\begin{array}{l}\text { Supported and modelling using assisted, choral, or pair } \\
\text { reading }\end{array}$ & & $x$ & $\mathrm{X}$ & & $x$ & $x$ & $x$ & $x$ & 6 & 75.0 \\
\hline 3 & Activated student loud reading & $x$ & $x$ & $X$ & $x$ & $x$ & $x$ & $x$ & $x$ & 8 & 100 \\
\hline 4 & Encouraged silent reading. & & & & $x$ & $x$ & $x$ & $x$ & $x$ & 5 & 62.5 \\
\hline 5 & Directed instruction and feedback in teaching new words & $x$ & $x$ & $\mathrm{X}$ & $x$ & & $x$ & $x$ & $x$ & 7 & 87.5 \\
\hline 6 & Motivated individual student strategy use & & & & $x$ & $x$ & $x$ & $x$ & $x$ & 5 & 62.5 \\
\hline
\end{tabular}

The classroom observation checklist and field note of the researchers indicated that the teacher first introduced the reading tasks in accordance with the reading strategies followed by teacher-student interaction, student-student interaction and independent practice of the scaffolding reading strategies.

On the first day, the teacher described the objectives and demonstrated the scaffolding reading strategies (including how, when, and where these strategies could be applied) to the students. Each scaffolding phase was explained to the students and a visible three-page list of strategies was fixed on the wall. And a one-page summary of the strategies was given to each student for independent practice. A sample paragraph was chosen from the students' textbook and the teacher explained on how and when to use the strategy by modelling each phase of the strategies through think-aloud procedure and discussion. The teacher is expected to prompt students to use the strategic processes regularly.

In the first and second lessons, both the teacher and the students were observed reluctant to properly apply the strategies. Hence, the one hour reading lesson was not used appropriately by many students and the teacher. For example, the first strategy in the Table, modelled reading fluency, shows that the strategy was not applied in the first and second lessons. To be more specific, during these lessons, students were not able to use the strategies while reading, and they did not finish within the allotted time; therefore, the teacher focused on teacher loud reading. But, during the subsequent lessons, students were regularly encouraged and guided of how to apply the strategies in their reading lessons. Then, they were able to apply the strategies developmentally to some extent.

During the while reading stage, the teacher encouraged modelled reading, student loud reading, choral reading, pair reading, and guided reading. She modelled teacher loud reading to facilitate appropriate spelling, and pronunciation. It was taught to gauge the speed with which a short passage is reproduced into spoken language often studied by making students read passages aloud and by calculating the average number of words that she/he read accurately within a minute.

In the post-reading strategy stage, the teacher motivated the students to practice pair/group oral reading in which the students were arranged to sit in pairs/groups and shown to use the short paragraph with the reading strategies' list. A student from the group read to the group members, and others gave corrections to ensure the speed with accurate pronunciation and meanings of difficult words. The teacher guided and assisted the students in their use of the strategy. The teacher made rounds and gave individual supports when needed. Finally, the teacher invited the students to reread individually to improve their speed and use the spelling and pronunciation within the text they read. Mostly, she used to give oral reading assignments by the end of the period and encouraged students to read to the class the following period before she began that daily lesson.

Generally, teacher observation on each strategy (i.e., directing, activating, modelling, loud reading, choral reading, silent reading, and independent strategy use) in the eight lessons revealed that students showed 
improvement. However, the researchers' observation disclosed that the students were not equally performing in all the scaffolding reading strategies (See Table 3). Furthermore, the teacher's and the students' reflection indicated that the students' fluency on the student independent strategy use $(62.5 \%)$ and individual silent reading $(62.5 \%)$ strategies was somewhat lower than their fluency on the teacher modelling and student reading aloud $(75 \%)$. As responses from the reflections confirmed, the students' performance on oral support and assisted choral and pair reading (75\%) and directed instruction and feedback to teach decoding of unknown words (87.5\%) was encouraging. This might have occurred because independent strategy use and individual silent reading demanded students' to use higher level of decoding and getting meaning from the passage without the support of the teacher. This goes consonant with the findings of Rodgers and Rodgers (2004). In addition, the applications of the scaffolding strategies which are new for both the teacher and the students have created a different scenario which is more demanding. There is some evidence that even short-term scaffolding intervention which lasted in 6 weeks showed encouraging improvements on students' oral reading fluency (Butler, 2007).

It seems that more scaffolding is needed to boost students' oral reading fluency in the sample school and other primary schools. The participating students reflected that they are beneficial because they have improved their speed, accuracy, fluency and strategy use. The teacher also appreciated teacher scaffolding as effective instrument and shared the same idea with the students except her opinion on time. She said, "Application of scaffolding is time consuming". Both the teacher and the students appreciated scaffolding intervention; they demanded its continuation.

To sum up, at the beginning of the intervention, the students had difficulty of using the strategies, because the strategies were new for them. Gradually, however, students started utilizing the strategy while reading the texts. Particularly at the beginning of the intervention, the teacher was not highly involved in helping the students apply the strategy and lacked providing guidance to some students when they needed. In addition, the researchers' classroom observation during the intervention and the teacher's and students' reflections also indicated that they had keen interest and motivation. In the end of the intervention, it was observed that many of the students were actively engaged while reading the texts to develop their oral reading fluency.

\section{CONCLUSIONS}

Generally, the findings of the pre-post test scores and the students' responses of the checklist and the teacher's observation in the lessons indicated that students had demonstrated gradual and steady improvement in their oral reading fluency. This finding is consistent with other research findings which indicate scaffolding strategy can improve students' reading fluency and comprehension (Dawit, 2014: Karim and Jallivand, 2014; Kim and White, 2008). The actual classroom observations in the intervention of the reading lessons made clear some evidence about the possible reasons that resulted in the improvement of the students' oral reading fluency scores. The scaffolded reading strategy intervention had created conducive situation to the teacher and the students to stay engaged in cooperation on the reading tasks with each other and with their teacher in each lesson. Whenever the teacher introduced the strategies, students were able to apply them as strategies for their oral reading fluency. The role of the teacher was replaced by students' responsibility and students were busily engaged in pair and group activities, student-student supports, feedback and independent reading on fluency. Previous research has also shown that when a teacher creates learning environments to students' level, their engagement and oral reading fluency increases (AIR, 2012; Butler, 2007; Dawit, 2014: Fuchs et al., 2001; Karim and Jallivand, 2014; Kim andWhite, 2008).

Based on the quantitative and qualitative findings of this study, therefore, it can be concluded that teacher's scaffolding on first cycle students' oral reading fluency is effective; it has significantly improved their reading fluency and strategy use. Therefore, it is recommended that English language teachers employ scaffolding strategies in teaching students' oral reading fluency at different grade levels of the primary cycle. Besides, it is also recommended teachers adapt and employ the scaffolding strategies at different levels than the first cycle. Finally, future research with extended intervention period with larger sample size at Grade 4 and at different grade levels and more teacher samples is recommended. The research implies the need to include other data gathering instruments with more sample sizes and more strategy use. Eventually, there should be training on scaffolding reading strategy use for the English language teachers, students and school leaders to make the reading lesson interactive.

As shown in the conclusion, teacher scaffolding has improved the students' oral reading fluency scores and strategy use. However, the researchers feel that there are some limitations of the study that include the small size of the participants of the study, limited intervention, and lack of in-depth interviews with the teacher and students.

\section{REFERENCES}

Abebe Damitew. (2012). Teaching reading skills in English as a foreign language through interactive classroom teaching versus plasma teaching with reference to Grade Ten Students in Addis Ababa (PhD Dissertation): Addis Ababa University.

Abiy Ygzaw (2007). Effects of teacher mediation on students' concepts and approaches to reading. VDM Verlag.

Adams, M.J. (1990). Beginning to read: Thinking and learning about print. Cambridge, MA: MIT Press.

American Institutes for Research (2011). USAID - AIR / Ethiopia Teach English for Life Learning (TELL): Classroom observation activity data analysis report. U.S. Agency for International Development.

Amlaku, B. (2010). Language policies and the role of English in Ethiopia. Presentation Paper at the $23^{\text {rd }}$ Annual Conference of IATEFLBESIE (19-21), Bielefeld, Germany.

Butler, T. W. (2007). Vocabulary and comprehension with students in primary grades: A comparison of instructional strategies (PhD Dissertation). University of Florida.

Chall, J. (1983). Strategies for Reading Development. New York: McGraw-Hill. 
Chanyalew Enyew et alo,

Chefena Hailemariam (1988). An Investigation of the Practices of Beginning Reading instructions in Government and Public Elementary Schools in Addis Ababa. Unpublished M.A. Thesis. Addis Ababa University.

Clay, M. (1990). The early detection of reading difficulties. Hong Kong: Heinemann

Cohen, L., Manion, L. and Morrison, K. (2007). Research Methods in Education (6 ${ }^{\text {th }}$ ed.) U.S.A: The Taylor and Francis e-Library.

Creswell, J.W. (2009). Research Design Qualitative, Quantitative, and Mixed Methods Approaches (3rd ed.). Thousand Oaks, CA: Sage.

Dawit Tibebu. (2014).The effects of explicit reading strategy instruction on reading comprehension of upper primary grade students. International Journal of Education 6(3): 120.

Dereje Negede. (2012). Primary EFL Teaching in Ethiopia: Policy and Practice Unpublished PhD Dissertation). Addis Ababa University.

Donaldson, R. (2011). What Classroom Observations Reveal About Primary Grade Reading Comprehension instruction within High Poverty Schools Participating in the Federal Reading First Initiative. All Graduate Theses and Dissertations. Paper

Eba Mijena. (2014). Practices and impeding factors in the teaching of English to young learners in the First Cycle Public Primary Schools at Nekemte Town, Western Ethiopia. Science, Technology and Arts Research Journal 3(2): 201-212.

Fitzgerald J. and Graves, M.F. (2004). Scaffolding reading experiences for English-language learners. Norwood, MA: Cristopher-Gorden Publishers, Inc.

Fuchs, L.S., Fuchs, D., Hosp, M.D., and Jenkins, J. (2001). Oral reading fluency as an indicator of reading competence: A theoretical, empirical, and historical analysis. Scientific Studies of Reading 5: 239-259.

Gemechis Teshome. (2014). Teaching reading skills in second cycle (5-8) of primary school in Oromiya Region: focus to East Wollega and Illuababor Zones. International Journal of Sciences: Basic and Applied Research 17(1): 95-109.

Gessesse Tadesse. (1999). The Effect of a process Approach to Teaching Reading on First Year Students at Kotebe College of Teacher Education (Unpublished PhD Dissertation). School of Graduate Studies. Addis Ababa University.

Hudson, R.F., Lave, H.B., and Pullen, P.C (2005). Reading fluency assessment and instruction: What, why, and how? The Reading Teacher 58(8): 1-13.

Institute for Research (AIR). (2012). Ethiopia Teach English for Life Learning (TELL) Program Field Study Report Policy and Practice in Ethiopia Building on the TELL Program and EGRA Results. USAID Ethiopia.

Juel, C. (1988). Learning to read and write: A longitudinal study of 54 children from first through fourth grade. Journal of Educational Psychology 80(4): 437-447.

Kim, J,S. and White, T.G. (2008). Scaffolding voluntary summer reading for children in grades 3 to 5 : An experimental study. Scientific Studies of Reading 12(1): $1-23$.
Sci. Technol. Arts Res. J., Oct-Dec 2015, 4(4): 200-207

Mesfin Derseh. (2008). The practice of teaching reading in English at first cycle primary schools: grade four in focus (Unpublished M.A Thesis). School of Graduate Studies, Addis Ababa University.

Michael Daniel. (2003). The Effect of Primary English Readers on Reading Skills in Ethiopia (Unpublished PhD Dissertation), University of Pretoria: South Africa.

Ministry of Education (2008). English Syllabus for Grades 14. Addis Ababa.

MoE (2011). English for Ethiopia. Teacher's Guide Grade 4. Addis Ababa.

MoE (2011). English for Ethiopia. Student Book. Grade Four. Addis Ababa.

Moore, A. S, DeStefano, J.and Adelman, E. (2010). Using opportunity to learn and early grade reading fluency to measure school effectiveness in Ethiopia, Guatemala and Nepal. The Academy for Educational Development (AED):EQUIP2.

Piper, B. (2010). Ethiopia early grade reading assessment. Data analytic report: language and early learning. North Carolina: RTI International.

Rodgers, A. and Rodgers, E.M. (2004). Scaffolding Literacy Instruction. Strategies for K-4 classrooms. Portsmouth: Heinemann.

Samuels, S.J. (2006). Introduction to reading fluency. Paper presented at the annual meeting of the International Reading Association, Chicago.

Schalach, T.D. (2008). START comprehending: students and teachers actively reading text. The reading Teacher 62(1): 20-31.

Stanovich, K. (1986). Matthew effects in reading: Some consequence of individual differences in the acquisition of literacy. Reading Research Quarterly 21(4): 360-407.

Talada, J. A. (2007). The relationship between oral reading fluency and comprehension (PhD Dissertation). Liberty University.

Transitional Government of Ethiopia. (1994). Education and Training Policy: Addis Ababa: EMPDA.

Tsehay Jemberu. (2012). Reading assessment of early grade children of five woredas in North Gonder of Amhara Region: A baseline data analytic report: Save the Children, Norway.

USAID/Ethiopia. (2011). Reading for Ethiopia's Achievement Developed (READ) Technical Assistance project. Presolicitation for Request for Proposals. Addis Ababa: USAID.

Williams, E. (1984). Reading in the Language Classroom London: Macmillan.

Wood, D., Bruner, J., and Ross, G. (1976). The Role of Tutoring in Problem-Solving. Journal of Child Psychology and Psychiatry 17: 89-100.

Vygotsky, L. S. (1978). Mind in society. The development of higher psychological processes, Cambridge MA: Harvard University Press.

Vygotsky, L.S. (1986). Thought and language. London, MA: MIT Press.

Zenebe Beyene.(2000). An investigation of the minimum threshold level towards the end of the first cycle: Reading skills in focus (Unpublished M.A. thesis), Addis Ababa University. 